\title{
Urea reduction ratio may be a simpler approach for measurement of adequacy of intermittent hemodialysis in acute kidney injury
}

Kelly V. Liang ${ }^{1 *}\left(\mathbb{D}\right.$, Jane H. Zhang ${ }^{2}$ and Paul M. Palevsky ${ }^{3}$

\begin{abstract}
Background: Assessment of adequacy of intermittent hemodialysis (IHD) is conventionally based upon urea kinetic models for calculation of single pool Kt $\mathrm{N}_{\text {urea }}(\mathrm{Kt} / \mathrm{N})$, with 1.2 accepted as minimum adequate clearance for thrice weekly IHD. In the Acute Renal Failure Trial Network (ATN) Study, adequacy of IHD in patients with acute kidney injury (AKI) was assessed using Kt $/ \mathrm{N}$. However, equations for $\mathrm{Kt} / \mathrm{N}$ require volume of distribution of urea, which is highly variable in AKI. Therefore, simpler methods are needed to assess adequacy of IHD in AKI. We assessed correlation of urea reduction ratio (URR) with $\mathrm{Kt} / \mathrm{N}$ and determined URR thresholds corresponding to $\mathrm{Kt} / \mathrm{N}$ values to determine if URR could be a simpler means to assess the delivered dose of IHD.

Methods: Using patients who received IHD for $2.5-6 \mathrm{~h}$ and with pre-dialysis $\mathrm{BUN} \geq 20 \mathrm{mg} / \mathrm{dL}$, we plotted URR against $\mathrm{Kt} / \mathrm{N}$. We determined URR thresholds (0.60 to 0.75 ) corresponding to $\mathrm{Kt} / \mathrm{V} \geq 1.2,1.3$, and 1.4. We generated receiver operating characteristic (ROC) curves for increasing URR values for each level of Kt $N$ to identify the corresponding thresholds of URR.

Results: There was strong correlation between URR and Kt $N$. ROC curves comparing URR with Kt $N \geq 1.2,1.3$, and 1.4 had area under the curves (AUC) of 0.99 . Sensitivity and specificity of URR $\geq 0.67$ for corresponding values of Kt $N \geq 1.2$ were 0.769 (95\% Cl: 0.745 to 0.793 ) and 0.999 (95\% Cl: 0.997 to 1.000), respectively and the sensitivity and specificity of URR $\geq 0.67$ for corresponding values of $\mathrm{Kt} / \mathrm{N} \geq 1.4$ were 0.998 ( $95 \%$ Cl: 0.995 to 1.000) and 0.791 ( $95 \%$ Cl: 0.771 to 0.811 ), respectively.

Conclusions: Targeting a URR $\geq 0.67$ provides a simplified means of assessing adequacy of IHD in patients with AKI. Use of URR will enhance ability to assess delivery of small solute clearance and improve adherence with clinical practice guidelines in AKI.
\end{abstract}

Keywords: Acute kidney injury, Renal replacement therapy, Adequacy, Kt/N, Urea reduction ratio

\section{Background}

Renal replacement therapy (RRT) is often required for the management of acute kidney injury (AKI). Depending on hemodynamic status, RRT may be provided by continuous dialysis (CRRT), hybrid forms of prolonged intermittent RRT (PIRRT) or intermittent dialysis (IHD). Assessment of adequacy of solute clearance in IHD is

\footnotetext{
* Correspondence: liangk@upmc.edu

${ }^{1}$ Renal-Electrolyte Division, Department of Medicine, University of Pittsburgh

School of Medicine, 3550 Terrace Street, Pittsburgh, PA 15213, USA

Full list of author information is available at the end of the article
}

conventionally based upon urea kinetic models for calculation of single pool Kt/V $\mathrm{V}_{\text {urea }}(\mathrm{Kt} / \mathrm{V})$ [1-5]. The Kidney Disease: Improving Global Outcomes (KDIGO) Clinical Practice Guidelines for AKI recommend achieving a threshold $\mathrm{Kt} / \mathrm{V}$ of at least $1.3 \mathrm{3x} /$ week or 3.9/week when delivering IHD in the setting of AKI [6]. These recommendations were substantially based upon data from the Veterans Affairs/National Institutes of Health Acute Renal Failure Trial Network (ATN) study, a multicenter randomized trial comparing strategies of more-intensive and less-intensive RRT in critically ill

(c) The Author(s). 2019 Open Access This article is distributed under the terms of the Creative Commons Attribution 4.0 International License (http://creativecommons.org/licenses/by/4.0/), which permits unrestricted use, distribution, and 
patients with AKI which targeted a delivered $\mathrm{Kt} / \mathrm{V}$ of 1.2-1.4 in patients receiving IHD [7].

Rigorous quantification of dialysis dose using urea kinetic modeling is based on assumptions related to net nitrogen balance and the generation and volume of distribution of urea that are not necessarily present in the critically ill patient with AKI $[8,9]$. Patients with AKI are often hypercatabolic and in net negative nitrogen balance; may have rates of urea that are not constant over time; have alterations in regional blood flow, particularly in the setting of hemodynamic instability, that may produce disequilibrium in urea distribution between body compartments, invalidating standard single-pool models; and may have a volume of distribution of urea $\left(\mathrm{V}_{\text {urea }}\right)$ that is variable and increased relative to patients with end-stage renal disease $[5,10,11]$. Thus, the applicability of the formal urea kinetic models and standard logarithmic estimating equations for calculation of $\mathrm{Kt} / \mathrm{V}$ that were developed in the end-stage renal disease setting to estimate adequacy of small solute clearance in patients with AKI receiving IHD is questionable. In particular, uncertainty regarding adjustments for $V_{\text {urea }}$ may introduce substantial error in the calculation of Kt/ $\mathrm{V}$ using standard estimating equations.

In this post hoc analysis of data from the ATN study, we sought to determine if use of the urea reduction ratio (URR), based only on measurement of pre- and post-dialysis BUN and independent of estimates of $\mathrm{V}_{\text {urear }}$, would provide a simpler but sufficiently reliable method for assessment of the delivered small solute clearance during IHD for patients with AKI. In this analysis, we assessed the correlation between URR and the systematically calculated values of $\mathrm{Kt} / \mathrm{V}$ in patients undergoing IHD in the ATN Study and determined URR thresholds that could be used as an alternative to $\mathrm{Kt} / \mathrm{V}$ to assess small solute clearance in critically ill patients with AKI undergoing IHD.

\section{Methods}

ATN study design

In the ATN Study, 1124 critically ill adults with severe AKI attributable to acute tubular necrosis in the setting of sepsis or one or more failed non-renal organ systems were randomized to strategies of either less-intensive or more-intensive RRT. Details of the design and primary results of the ATN study have been previously published [7]. Written informed consent was obtained prior to enrollment and randomization of all participants. Participants randomized to more-intensive RRT $(N=563)$ received continuous venovenous hemodiafiltration (CVVHDF) at an effluent flow rate of $35 \mathrm{~mL} / \mathrm{kg} / \mathrm{h}$ or sustained low-efficiency dialysis (SLED) on a 6-day-per-week schedule (every day except Sunday) when hemodynamically unstable, or IHD on a 6-day-per-week schedule (every day except Sunday) when hemodynamically stable. Participants randomized to the less-intensive strategy $(N=561)$ received CVVHDF at an effluent flow rate of $20 \mathrm{~mL} / \mathrm{kg} / \mathrm{h}$ or SLED on a 3-day-per-week schedule (every other day except Sunday) when hemodynamically unstable, or IHD on a 3-day-per-week schedule (every other day except Sunday) when hemodynamically stable. In each treatment arm, IHD was prescribed with a targeted single-pool, variable-volume (spvv) Kt/V of 1.2-1.4 per treatment.

\section{Calculation of $\mathrm{Kt} / \mathrm{V}$}

$\mathrm{Kt} / \mathrm{V}$ was assessed at least three times per week during the first two weeks of study therapy and at least weekly thereafter using the second generation logarithmic (Daugirdas) equation:

$$
\begin{aligned}
\mathrm{Kt} / \mathrm{V}= & -\ln (\mathrm{R}-0.008 \times \mathrm{t}) \\
& +(4-3.5 \times \mathrm{R}) \times 0.55 \times \mathrm{UF} / \mathrm{V}_{\text {urea }}
\end{aligned}
$$

where $R$ is the ratio of post-dialysis $\mathrm{BUN}\left(\mathrm{BUN}_{\text {post }}\right)$ divided by pre-dialysis $\mathrm{BUN}\left(\mathrm{BUN}_{\mathrm{pre}}\right), t$ is the dialysis session duration in hours, $U F$ is the ultrafiltration volume in liters, and $V_{\text {urea }}$ is the estimated volume of distribution of urea $[8,9]$. Blood samples for BUN were obtained immediately pre- and post-dialysis, with the post-dialysis BUN sample obtained using the slow-flow/ stop-pump technique [14] to prevent sample dilution with recirculated blood and to minimize the variable effects of urea rebound. $V_{\text {urea }}$ was initially estimated as $55 \%$ of pre-morbid body weight plus edema weight, where edema weight was calculated as pre-morbid body weight subtracted from current body weight and was recalculated each treatment. In patients with morbid obesity, defined as actual weight $>130 \%$ of ideal body weight (IBW), an adjusted pre-morbid body weight was calculated as IBW plus $25 \%$ of the difference between ideal and actual pre-morbid weight with IBW calculated based on height, gender, and frame size with adjustment for limb amputation [15]. The rationale for this correction is based on the reduction in the percentage body weight comprised by water (and hence $V_{\text {urea }}$ ) as the percentage body fat increases.

\section{Calculation of urea reduction ratio (URR)}

The urea reduction ratio was calculated as the quotient of the difference between the $B U N_{p r e}$ and the $B U N_{\text {post }}$ divided by the $B \mathrm{BN}_{\mathrm{pre}}$ :

$$
\mathrm{URR}=\left(\mathrm{BUN}_{\text {pre }}-\mathrm{BUN}_{\text {post }}\right) / \mathrm{BUN}_{\text {pre }}
$$

using the same BUN values used to calculate Kt/V.

\section{Statistical methods}

We compared paired Kt/V and URR measurements from all IHD treatments with measured pre- and post-dialysis 
BUNs, excluding treatments that were $<2.5 \mathrm{~h}$ or $>6 \mathrm{~h}$ in duration. In addition, we excluded data from IHD treatments with pre-dialysis BUN values $<20 \mathrm{mg} / \mathrm{dL}$ as the reliability of URR and $\mathrm{Kt} / \mathrm{V}$ calculations is markedly reduced when the pre-dialysis BUN is $<20 \mathrm{mg} / \mathrm{dL}$. We report demographic and baseline clinical data as mean \pm standard deviation, median (interquartile range) and number (percent) as appropriate. We examined the relationship between URR and Kt/V using linear and semi$\log$ plots and assessed the performance of URR against $\mathrm{Kt} / \mathrm{V}$ thresholds of 1.2, 1.3 and 1.4 by generating receiver operating characteristic (ROC) curves and calculating the area under the curve (AUC) for each $\mathrm{Kt} / \mathrm{V}$ value. We then identified values of URR that maximized sensitivity (fraction of measurements less than a given URR value when $\mathrm{Kt} / \mathrm{V}$ was less than the target threshold) and specificity (fraction of measurements greater than a given URR value when $\mathrm{Kt} / \mathrm{V}$ was greater than the target threshold) for $\mathrm{Kt} / \mathrm{V}$ values of 1.2, 1.3 and 1.4.

\section{Results}

\section{Number of Kt/V and URR measurements}

Pre- and post-dialysis BUN measurements were obtained and $\mathrm{Kt} / \mathrm{V}$ was calculated at least once during IHD treatments in 589 of the 1124 patients who participated in the ATN study. Characteristics of these patients are summarized in Table 1 . There were a total of 2113 preand post-dialysis measurements in these 589 obtained during treatments with a duration between 2.5 and $6 \mathrm{~h}$, a pre-dialysis $\mathrm{BUN} \geq 20 \mathrm{mg} / \mathrm{dL}$, and with documented preand post-dialysis weights to permit calculation of $\mathrm{Kt} / \mathrm{V}$. The mean number of Kt/V and URR measurements per patient was $3.6 \pm 3.0$.

\section{Distribution of $\mathrm{Kt} / \mathrm{V}$ and URR measurements}

The overall mean \pm standard deviation (SD) Kt/V for the first treatment was $1.13 \pm 0.32$ and for subsequent treatments was $1.32 \pm 0.36$, with a mean $\mathrm{Kt} / \mathrm{V}$ of $1.25 \pm 0.35$ across all treatments. The $\mathrm{Kt} / \mathrm{V}$ values were normally distributed for both first and subsequent treatments (Fig. 1). There were no significant differences between average $\mathrm{Kt} / \mathrm{V}$ achieved for first or subsequent IHD treatments between the more intensive and less intensive RRT dose arms (data not shown). For this reason, all subsequent analyses were performed without stratification by treatment assignment.

\section{Relationship between URR and Kt/V}

There was a curvilinear relationship between URR and $\mathrm{Kt} / \mathrm{V}$ (Fig. 2). ROC curves comparing URR with thresholds of $\mathrm{Kt} / \mathrm{V} \geq 1.2,1.3$, and 1.4 all had areas under the curves (AUC) of approximately 0.99 (Figs. 3a-c). The corresponding URR values for the range of $\mathrm{Kt} / \mathrm{V}$ achieved in the ATN trial ranged from 0.60 to 0.75 . The
Table 1 Characteristics of patients receiving intermittent hemodialysis (IHD) included in analysis

\begin{tabular}{ll}
\hline & \multicolumn{1}{l}{ Patients receiving } \\
& IHD (N=589) \\
\hline Age (years) & $64.3 \pm 13.1$ \\
Gender & $108(18.4 \%)$ \\
Male & $480(81.6 \%)$ \\
Female & \\
Race or Ethnic Group & $477(81.0 \%)$ \\
White, non-Hispanic & $80(13.6 \%)$ \\
Black, non-Hispanic & $14(2.4 \%)$ \\
Hispanic & $12(2.0 \%)$ \\
Other & $85.0 \pm 18.8$ \\
Pre-morbid Weight (kg) & 2113 \\
Number of treatments with Kt $N$ measured & \\
Number of treatments with Kt $N$ measured per patient \\
Mean \pm SD & $3.6 \pm 3.0$ \\
Median (IQR) & $3(2-5)$ \\
Kt $N$ & \\
Mean $\pm S D$ & $1.25 \pm 0.35$ \\
Median (IQR) & $1.25(1.05-1.43)$ \\
URR & \\
Mean $\pm S D$ & $0.64 \pm 0.10$ \\
Median (IQR) & $0.66(059-0.71)$ \\
\hline
\end{tabular}

$I H D=$ intermittent hemodialysis, $I Q R=$ interquartile range, $S D=$ standard deviation, $U R R=$ urea reduction ratio

sensitivity and specificity for URR values between 0.60 and 0.75 for $\mathrm{Kt} / \mathrm{V}$ thresholds of $1.2,1.3$ and 1.4 are provided in Table 2 . The specificity for a $\mathrm{Kt} / \mathrm{V} \geq 1.2$ was maximized when the URR was $\geq 0.67$ (specificity 0.999 ; 95\% CI: 0.997 to 1.000 ) and for a Kt/V $\geq 1.4$ when the URR was $\geq 0.72$ (specificity $0.995 ; 95 \%$ CI: 0.991 to 0.998). Similarly, the sensitivity for a Kt/V threshold of 1.4 was maximized at unity for URR values $<0.67$.

\section{Discussion}

Our data demonstrate that there is a tight correlation between paired URR and Kt/V values and that measurement of URR provides a simpler method with adequate reliability for assessment of the delivered small solute clearance during intermittent hemodialysis in critically ill patients with AKI. This relationship is not unexpected, as the estimating equation used for calculating $\mathrm{Kt} / \mathrm{V}$ is a function of the ratio between post-dialysis and pre-dialysis BUN, which is equal to $1-$ URR $[7,8]$.

ROC curves evaluating the performance of URR relative to $\mathrm{Kt} / \mathrm{V}$ thresholds of 1.2, 1.3, and 1.4 had AUC of $>0.99$. Based on our data, a URR of $\geq 0.67$ corresponded to a Kt/V $\geq 1.2$ with $>99 \%$ accuracy with URR values of $0.67-0.72$ corresponding to $\mathrm{Kt} / \mathrm{V}$ values of $1.2-$ 


\section{ATN Study - Delivered Kt/V}

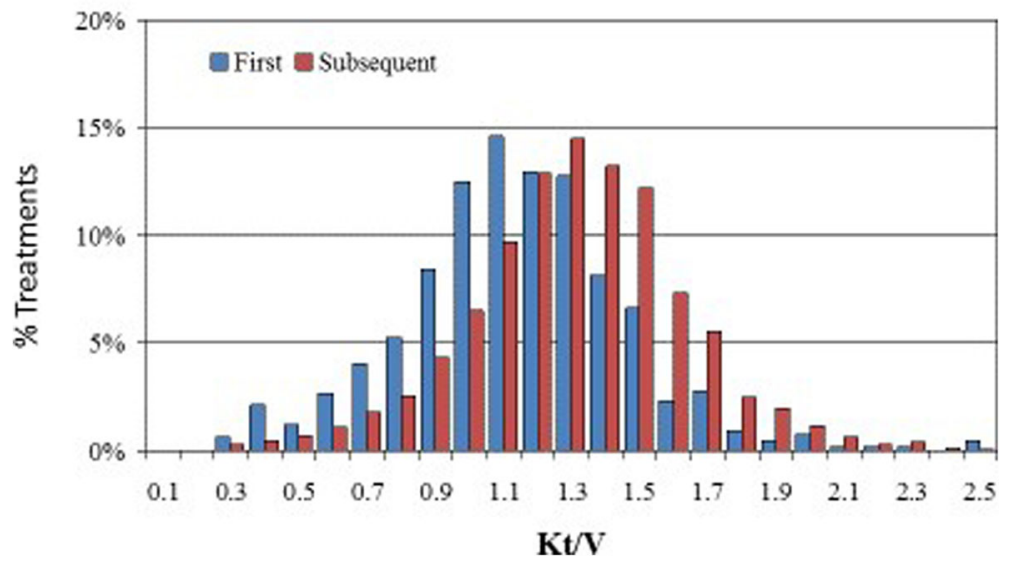

Fig. 1 Distribution of Delivered Kt/N During Intermittent Hemodialysis in the ATN Trial. The overall mean \pm standard deviation (SD) Kt/N for the first treatment was $1.13 \pm 0.32$ and for subsequent treatments was $1.32 \pm 0.36$, with a range of 0.3 to 2.5 . The $\mathrm{Kt} / \mathrm{V}$ values were normally distributed for both first and subsequent treatments

1.4. The KDIGO Clinical Practice Guidelines for AKI recommend delivery of $\mathrm{Kt} / \mathrm{V}$ of at least 3.9 per week, corresponding to a $\mathrm{Kt} / \mathrm{V}$ of $>1.3$ on a thrice weekly dialysis schedule [6]. This would correspond to delivery of hemodialysis with a URR $>0.69$ three times per week.

Measurement of adequacy of small solute clearance during intermittent hemodialysis is most rigorously based on formal urea kinetic modeling. However, many of the assumptions underlying these models in the stable outpatient with end-stage renal disease do not apply to critically ill patients with AKI $[3,16]$. In particular, urea kinetic models assume the existence of a relative steady state during the modeling period, with the patient remaining in neutral nitrogen balance and the pre-dialysis state remaining relatively stable over repeated cycles of hemodialysis. These assumptions are often not valid in critically ill patients with AKI, the majority of whom are hypercatabolic and are in negative nitrogen balance or

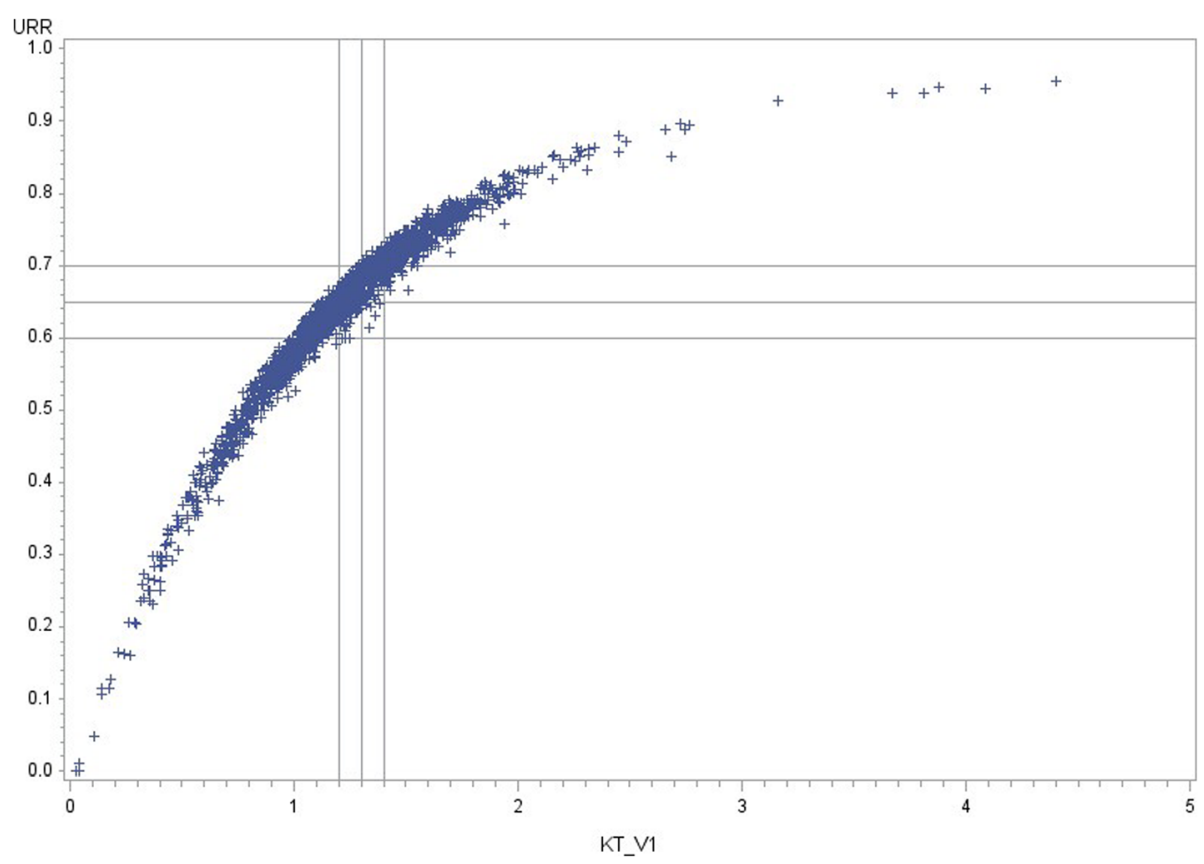

Fig. 2 Plot of URR vs. Kt/N. There was a curvilinear relationship between URR and Kt/N 

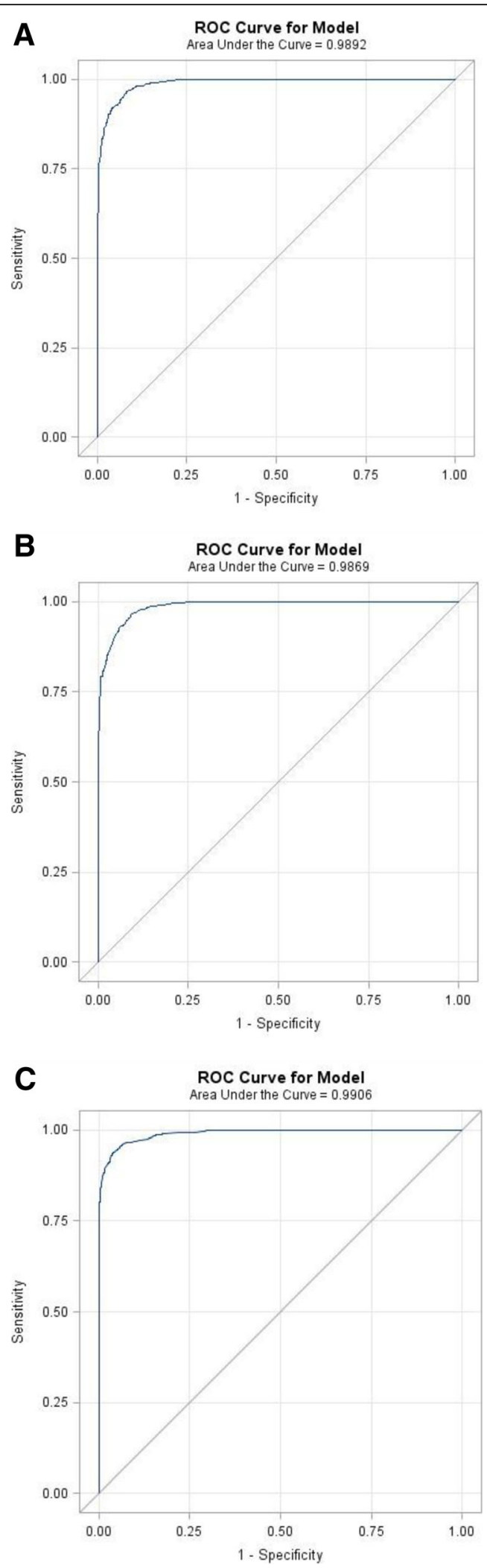

Fig. 3 Receiver Operating Characteristic (ROC) Curves for Increasing Values of URR for $\mathrm{Kt} / \mathrm{V}$ values $\geq 1.2,1.3$, and 1.4. a) Area under the curve (AUC) of the ROC curve for Kt $N \geq 1.2$ was 0.9892. b) AUC of the ROC curve for $\mathrm{Kt} / N \geq 1.3$ was 0.9869. c) AUC of the ROC curve for $\mathrm{Kt} / \mathrm{N} \geq 1.4$ was 0.9906

have variable rates of urea generation [13]. Furthermore, alterations in regional blood flow, particularly in patients who are hemodynamically unstable, may produce disequilibrium in urea distribution between body fluid compartments, invalidating standard single pool models [13]. In addition, unlike patients with end-stage renal disease on chronic hemodialysis, the volume of distribution of urea $\left(\mathrm{V}_{\text {urea }}\right)$ in patients with AKI may exceed total body water [12] and may be highly variable due to variations in volume status over time. Thus, estimates of small solute kinetics in critically ill patients with AKI using formal urea kinetic models are inadequately validated as is the use of standard estimating equations $[8,9]$.

In the VA/NIH Acute Renal Failure Trial Network Study, Kt/V was estimated at least three times per week in patients receiving IHD during the first two weeks of study therapy and then at least weekly thereafter using a second generation logarithmic estimating equation. In order to adjust for variations in volume status, $V_{\text {urea }}$ was re-estimated each treatment using an iterative process incorporating estimates of edema weight based on the difference between pre-morbid and post-dialysis body weight. The calculation of $\mathrm{Kt} / \mathrm{V}$ used during the study was therefore cumbersome and not readily transferable to clinical practice. While the use of URR is less precise in estimating small solute clearance in intermittent renal replacement therapy, we have shown satisfactory correlation between paired values of URR and $\mathrm{Kt} / \mathrm{V}$ in more than 3600 dialysis sessions. The use of URR is readily transferable to clinical practice and would facilitate assessment of the delivered dose of intermittent renal replacement therapy in the acute setting and the implementation of quality improvement processes to ensure appropriate delivery of therapy.

Limitations of our analysis must be noted. First and foremost, despite the fact that $\mathrm{Kt} / \mathrm{V}$ calculation in the ATN study was rigorously protocolized, $\mathrm{Kt} / \mathrm{V}$ was still calculated using a second generation logarithmic estimating equation rather than using formal urea kinetic modeling. Secondly, errors in estimation of $\mathrm{Kt} / \mathrm{V}$ may have resulted from the protocolized methodology used in the ATN study to estimate $\mathrm{V}_{\text {urea }}$. Third, all dialysis treatments utilized catheters and catheter recirculation can both reduce the delivered dose of dialysis and interfere with ascertainment of post-dialysis BUN. However, recirculation will not affect the relationship between the measured $\mathrm{Kt} / \mathrm{V}$ and URR. Furthermore, post-dialysis sampling during the ATN study was 
Table 2 Sensitivity/specificity of URR for detecting Kt/N

\begin{tabular}{|c|c|c|c|c|c|c|}
\hline \multirow[t]{2}{*}{ URR } & \multicolumn{2}{|l|}{$\mathrm{Kt} / \mathrm{N} \geq 1.2$} & \multicolumn{2}{|l|}{$\mathrm{Kt} / \mathrm{N} \geq 1.3$} & \multicolumn{2}{|l|}{$\mathrm{Kt} / \mathrm{N} \geq 1.4$} \\
\hline & Sensitivity $(95 \% \mathrm{Cl})$ & Specificity $(95 \%$ Cl) & Sensitivity $(95 \% \mathrm{CI})$ & Specificity $(95 \% \mathrm{Cl})$ & Sensitivity $(95 \% \mathrm{Cl})$ & Specificity (95\% Cl) \\
\hline 60 & $1.000(1.000-1.000)$ & $0.613(0.582-0.643)$ & $1.000(1.000-1.000)$ & $0.447(0.421-0.474)$ & $1.000(1.000-1.000)$ & $0.376(0.352-0.400)$ \\
\hline 0.61 & $0.998(0.995-1.000)$ & $0.710(0.681-0.738)$ & $1.000(1.000-1.000)$ & $0.520(0.494-0.547)$ & $1.000(1.000-1.000)$ & $0.437(0.413-0.46$ \\
\hline 0.62 & 0.994 (0.989-0.998) & $0.772(0.746-0.799)$ & $0.999(0.997-1.000)$ & $0.569(0.543-0.596)$ & $1.000(1.000-1.000)$ & $0.479(0.455-0.50$ \\
\hline 63 & $0.983(0.976-0.990)$ & $0.851(0.829-0.873)$ & $0.999(0.997-1.000)$ & $0.636(0.610-0.662)$ & $1.000(1.000-1.000)$ & $0.535(0.511-0.560)$ \\
\hline 0.64 & $0.964(0.954-0.975)$ & $0.905(0.887-0.924)$ & $0.998(0.995-1.000)$ & $0.693(0.668-0.717)$ & $1.000(1.000-1.000)$ & $0.583(0.559-0.60$ \\
\hline 65 & $14-0.943)$ & 0.953 & 0.993 & 0.757 & 1.000 & $0.664)$ \\
\hline 0.66 & $0.861(0.842-0.881)$ & $0.988(0.981-0.995)$ & $0.978(0.968-0.988)$ & $0.835(0.815-0.855)$ & $1.000(1.000-1.000)$ & $0.714(0.691-0.736$ \\
\hline 57 & $0.769(0.745-0.793)$ & $0.999(0.997-1.000)$ & $0.950(0.936-0.965)$ & $0.910(0.894-0.925)$ & $0.998(0.995-1.000)$ & $0.791(0.771-0.81$ \\
\hline 68 & $0.769(0.745-0.793)$ & $0.999(0.997-1.000)$ & $0.912(0.893-0.931)$ & $0.955(0.944-0.966)$ & $0.994(0.987-1.000)$ & $0.848(0.831-0.866)$ \\
\hline 69 & 0.769 & 0.99 & $0.834(0.80$ & 0.990 & 0.972 & $0.912(0.8$ \\
\hline 0.70 & $0.768(0.745-0.793)$ & $0.999(0.997-1.000)$ & $0.834(0.809-0.859)$ & $0.990(0.984-0.995)$ & $0.937(0.917-0.956)$ & $0.960(0.950-0.969$ \\
\hline 0.71 & 73) & 0.99 & 859) & 0.9 & 0.8 & $0.992)$ \\
\hline 0.72 & $0.769(0.745-0.793)$ & $0.999(0.997-1.000)$ & $0.834(0.809-0.859)$ & 0.990 (0.984-0.995) & $0.735(0.700-0.770)$ & $0.995(0.991-0.998$ \\
\hline 73 & $0.769(0.745-0.793)$ & $0.999(0.997-1.000)$ & $0.834(0.809-0.859)$ & $0.990(0.984-0.995)$ & $0.735(0.700-0.770)$ & $0.995(0.991-0.998)$ \\
\hline 0.74 & $0.769(0.745-0.793)$ & $0.999(0.997-1.000)$ & $0.834(0.809-0.859)$ & 0.990 (0.984-0.995) & $0.735(0.700-0.770)$ & $0.995(0.991-0.998$ \\
\hline 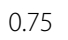 & $0.769(0.745-0.793)$ & $0.999(0.997-1.000)$ & $0.834(0.809-0.859)$ & 0.990 (0.984-0.995) & $0.735(0.700-0.770)$ & $0.995(0.991-0.99$ \\
\hline
\end{tabular}

rigorously protocolized using standard slow-flow (blood pump at $<100 \mathrm{~mL} / \mathrm{min}$ ) or stop-pump sampling techniques to minimize the effect of catheter recirculation on ascertainment of the post-dialysis BUN concentration. Finally, since we relied on repeated measurements in individual patients, this may have introduced a degree of covariance between URR and $\mathrm{Kt} / \mathrm{V}$ measurements that was not accounted for in our analytic approach. However, our data represents the largest dataset of rigorously measured pre- and post-dialysis BUNs and of systematically calculated estimates of $\mathrm{Kt} / \mathrm{V}$ with a wide variance in both URR and $\mathrm{Kt} / \mathrm{V}$ values. In addition, given the technical aspects of URR and Kt/V measurement, biological factors within individual patients are unlikely to have significantly contributed to covariance.

\section{Conclusions}

In summary, we believe that the findings of our study validate the use of URR as a simpler means of assessing delivery of small solute clearance during intermittent hemodialysis in patients with AKI. Although this approach underestimates solute clearance associated with ultrafiltration, it should be recognized that multiple assumptions used in determination of $\mathrm{Kt} / \mathrm{V}$, such as the relationship of volume of distribution of urea to total body weight, do not hold in critically ill patients with AKI. The use of URR, which can be easily calculated, will enhance the ability to assess adequacy of acute dialysis treatments, improve adherence with the KDIGO clinical practice guidelines for delivered dose of intermittent renal replacement therapy in AKI, and facilitate implementation of quality assurance and performance improvement processes in the acute setting. Although the clearance of toxins is one of the key roles of dialysis in AKI, other important factors should also be considered when prescribing IHD in the critically ill population. Specifically, maintaining adequate fluid balance via fluid removal with dialysis, as well as considering the effect of more intensive hemodialysis on antibiotic clearance and efficacy of treatment of sepsis needs to be factored into decisions when prescribing IHD in AKI. Nevertheless, the need to achieve adequate small solute clearance remains a fundamental aspect in the prescription and monitoring of acute hemodialysis in critically ill patients with AKI. Our findings suggest that URR, which may be more simply calculated than $\mathrm{Kt} / \mathrm{V}$, is sufficient for assessment of delivery of small solute clearance. Our findings are of relevance to both clinical care and clinical research by simplifying the methods used to quantify small solute clearance during intermittent renal replacement therapy in critically ill patients with AKI.

\section{Abbreviations}

AKI: acute kidney injury; ATN Study: Veterans Affairs/National Institutes of Health Acute Renal Failure Trial Network Study; AUC: Area under the curve; BUN: Blood urea nitrogen; IHD: Intermittent hemodialysis; KDIGO: Kidney Disease Improving Global Outcomes; PIRRT: Prolonged intermittent renal replacement therapy; ROC: Receiver operating characteristic curve; RRT: Renal replacement therapy; URR: Urea reduction ratio; VA: Veterans Affairs

\section{Acknowledgments}

We gratefully acknowledge all the patients who participated in the Acute Renal Failure Trial Network (ATN) Study whose data was utilized in this post hoc analysis. 


\section{Funding}

This work was supported by K23 grant DK092278-01A1 [Liang]. The ATN Study was funded by the Cooperative Studies Program of the Veterans Affairs Office of Research and Development (CSP \#530) and by the National Institute of Diabetes and Digestive and Kidney Diseases (interagency agreement Y1-DK-3508-01). The funding sources had no role in the design of the study; collection, analysis, and interpretation of data; or writing of the manuscript.

\section{Availability of data and materials}

The datasets used and/or analyzed during the current study are available from the corresponding author on reasonable request.

\section{Authors' contributions}

KVL and PMP conceived and designed the analysis; JHZ performed statistical analyses of the data; $\mathrm{KVL}, J \mathrm{HZ}$ and PMP interpreted the data; $\mathrm{KVL}$ prepared the first draft of the manuscript; $K V L, J H Z$ and PMP critically reviewed and revised the manuscript. All authors read and approved the final manuscript.

\section{Authors' information}

PMP is Chief, Renal Section at the VA Pittsburgh Healthcare System and Professor of Medicine at the University of Pittsburgh School of Medicine and was the Principal Investigator and Study Chair of the VA/NIH Acute Renal Failure Trial Network (ATN) study.

\section{Ethics approval and consent to participate}

The Human Rights Committee at the West Haven VA Cooperative Studies Program (CSP) Coordinating Center and the institutional review boards at the VA Pittsburgh Healthcare System (chair's office) and at each of the participating study sites approved the ATN Study and authorized data analyses performed by study investigators. Written informed consent was obtained prior to enrollment and randomization of all participants.

\section{Consent for publication}

Not applicable.

\section{Competing interests}

PMP reports serving as a consultant for Baxter, Inc., GE Healthcare and Novartis. KVL and JHZ declare that they have no competing interests.

\section{Publisher's Note}

Springer Nature remains neutral with regard to jurisdictional claims in published maps and institutional affiliations.

\section{Author details}

${ }^{1}$ Renal-Electrolyte Division, Department of Medicine, University of Pittsburgh School of Medicine, 3550 Terrace Street, Pittsburgh, PA 15213, USA. ${ }^{2}$ Cooperative Studies Program Coordinating Center (151A), VA Connecticut Healthcare System, 950 Campbell Avenue, West Haven, CT 06516, USA. ${ }^{3}$ Renal Section (111F-U) VA Pittsburgh Healthcare System, University Drive, Pittsburgh, PA 15240, USA.

Received: 28 July 2018 Accepted: 27 February 2019

Published online: 06 March 2019

\section{References}

1. Keshaviah PR, Nolph KD, Van Stone JC. The peak concentration hypothesis: a urea kinetic approach to comparing the adequacy of continuous ambulatory peritoneal dialysis (CAPD) and hemodialysis. Perit Dial Int. 1989:9:257-60

2. Casino FG, Lopez T. The equivalent renal urea clearance: a new parameter to assess dialysis dose. Nephrol Dial Transplant. 1996;11:1574-81.

3. Clark WR, Mueller BA, Kraus MA, Macias WL. Dialysis prescription and kinetics in acute renal failure. Adv Ren Replace Ther. 1997;4(2 Suppl 1):64-71.

4. Gotch FA. The current place of urea kinetic modelling with respect to different dialysis modalities. Nephrol Dial Transplant. 1998;13(Suppl 6):10-4

5. Gotch FA, Sargent JA, Keen ML. Whither goest Kt/N? Kidney Int Suppl. 2000;76:S3-S18.

6. Kidney Disease. Improving global outcomes (KDIGO) Acute kidney injury work group. KDIGO clinical practice guideline for Acute kidney injury. Kidney Int Suppl. 2012;2:1-138.
7. VA/NIH Acute Renal Failure Trial Network, Palevsky PM, Zhang JH, O'Connor TZ, et al. Intensity of renal support in critically ill patients with acute kidney injury. N Engl J Med. 2008;359(1):7-20.

8. Daugirdas JT. Simplified equations for monitoring Kt/N, PCRn, eKTN , and ePRCRn. Adv Ren Replace Ther. 1995;2:295-304.

9. Daugirdas JT. Second generation logarithmic estimates of single-pool variable volume Kt/N: an analysis of error. J Am Soc Nephrol. 1993;4:1205-13.

10. Palevsky PM, Liu KD, Brophy PD, et al. KDOQI US commentary on the 2012 KDIGO clinical practice guideline for acute kidney injury. Am J Kidney Dis. 2013;61(5):649-72.

11. National Kidney Foundation. KDOQI Clinical Practice Guideline for Hemodialysis Adequacy: 2015 update. Am J Kidney Dis. 2015;66(5):884-930.

12. Himmelfarb J, Evanson J, Hakim RM, Freedman S, Shyr Y, Ikizler TA. Urea volume of distribution exceeds total body water in patients with acute renal failure. Kidney Int. 2002:61(1):317-23.

13. Himmelfarb J, Ikizler TA. Quantitating urea removal in patients with acute renal failure: lost art or forgotten science? Semin Dial. 2000;13(3):147-9.

14. Kapoian T, Steward CA, Sherman RA. Validation of a revised slow-stop flow recirculation method. Kidney Int. 1997;52(3):839-42.

15. Osterkamp LK. Current perspective on assessment of human body proportions of relevance to amputees. J Am Diet Assoc. 1995;95(2):215-8.

16. Clark WR, Mueller BA, Kraus MA, Macias WL. Renal replacement therapy quantification in acute renal failure. Nephrol Dial Transplant. 1998;13(Suppl 6):86-90.

\section{Ready to submit your research? Choose BMC and benefit from:}

- fast, convenient online submission

- thorough peer review by experienced researchers in your field

- rapid publication on acceptance

- support for research data, including large and complex data types

- gold Open Access which fosters wider collaboration and increased citations

- maximum visibility for your research: over $100 \mathrm{M}$ website views per year

At $\mathrm{BMC}$, research is always in progress.

Learn more biomedcentral.com/submissions 